University of Nebraska - Lincoln

DigitalCommons@University of Nebraska - Lincoln

USDA National Wildlife Research Center - Staff Publications
U.S. Department of Agriculture: Animal and Plant Health Inspection Service

February 2005

\title{
Influence of the number of repellent-treated and untreated food or water containers on intake by the European starling
}

Arla G. Hile

USDA/APHIS/WS, National Wildlife Research Center

Michael G. Tordoff

Monell Chemical Senses Center

Follow this and additional works at: https://digitalcommons.unl.edu/icwdm_usdanwrc

Part of the Environmental Sciences Commons

Hile, Arla G. and Tordoff, Michael G., "Influence of the number of repellent-treated and untreated food or water containers on intake by the European starling" (2005). USDA National Wildlife Research Center Staff Publications. 13.

https://digitalcommons.unl.edu/icwdm_usdanwrc/13

This Article is brought to you for free and open access by the U.S. Department of Agriculture: Animal and Plant Health Inspection Service at DigitalCommons@University of Nebraska - Lincoln. It has been accepted for inclusion in USDA National Wildlife Research Center - Staff Publications by an authorized administrator of DigitalCommons@University of Nebraska - Lincoln. 


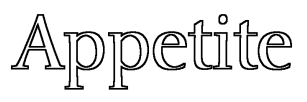

ELSEVIER

Appetite 45 (2005) 81-85

www.elsevier.com/locate/appet

Research Report

\title{
Influence of the number of repellent-treated and untreated food or water containers on intake by the European starling
}

\author{
Arla G. Hile ${ }^{\mathrm{a}, *}$, Michael G. Tordoff ${ }^{\mathrm{b}}$ \\ ${ }^{a}$ USDA/APHIS/WS, National Wildife Research Center, Philadelphia Field Station, 3500 Market St., Philadelphia, PA 19104, USA \\ ${ }^{\mathrm{b}}$ Monell Chemical Senses Center, 3500 Market St., Philadelphia, PA 19104, USA
}

Received 11 October 2004; revised 22 November 2004; accepted 18 February 2005

\begin{abstract}
The availability of multiple sources of food and drink has a profound influence on choice behavior in rodents. It is not known how other taxa might respond to the same kind of variation in availability. We tested European starlings (Sturnus vulgaris) with various combinations of unadulterated and repellent-treated $(0.025 \%$ citronellyl acetate) resources. In Experiment 1, birds drank more plain than repellent-treated water than when given (a) 2 bottles of plain water and 2 of repellent-water, or (b) 3 bottles of plain water and 1 of repellent-water. However, they drank more repellent than water when given 3 bottles of repellent-water and 1 of plain water. Thus, the aversion to the repellent became indifference when repellent-water was abundant. In Experiment 2, birds ate more untreated than treated food when given (a) 1 cup of untreated food and 1 cup of treated food or (b) 2 cups of untreated food and 1 of treated food. They ate equal amounts of untreated and treated food when given 1 cup of untreated food and 2 cups of treated food. These results demonstrate the effect of relative availability on choice, and imply that availability should be considered when using repellents.
\end{abstract}

Published by Elsevier Ltd.

Keywords: Birds; Food choice; Pest control; Taste; Foraging

\section{Introduction}

There is a growing body of evidence showing that the relative availability of nutrients has a dramatic effect on intake. In one study, mice were given a series of tests with a choice between water and 1 or 2 bottles of a solution. The solution was a representative sweet, sour, bitter, or salty taste. Irrespective of the solution used, the mice drank more of it when they were presented with 2 bottles of solution and 1 of water than 1 bottle of each liquid or 1 bottle of solution and 2 of water (Tordoff \& Bachmanov, 2003a). Similarly, rats drank more sucrose and became fatter when given 5 bottles of sucrose solution and 1 of water than when given 1 bottle of sucrose solution and 5 of water (Tordoff, 2002). Under some circumstances the normal avoidance of unpalatable stimuli can be reversed by manipulating

\footnotetext{
* Corresponding author

E-mail addresses: ahile@monell.org (A.G. Hile), tordoff@monell.org (M.G. Tordoff).
}

0195-6663/\$ - see front matter Published by Elsevier Ltd. doi:10.1016/j.appet.2005.03.009 the number of sources available. Intake of a $10 \%$ ethanol solution, which is considered unpalatable to rodents based on the results of 2-bottle tests, varies as a function of the number of bottles containing the ethanol. Thus, the aversion to ethanol observed when relatively few ethanol-containing bottles are available disappears as the number of bottles with ethanol increases. Intake from each unpalatable source is low but the sum of intakes from all available unpalatable sources is much higher than from the plain source (Tordoff \& Bachmanov, 2003b).

The implication for wildlife management is clear: Intense, large-scale use of the same repellent across the landscape could influence whether animals avoid consuming the resource. This is particularly true because the ethical and legal landscape favors the use of repellents rather than toxicants; while animals are physiologically limited in their ability to ingest toxicants, the same is not true for repellents (Provenza et al., 2003). For example, if a particular chemical repellent was applied in a few areas, it should be effective in deterring animals from causing damage. As progressively more of the same repellent is applied across the landscape, animals may change their behavior and in some cases the repellent may become their preferred flavor. 
Since so few repellents are currently available, this scenario is alarmingly realistic.

Studies exploring the effect of availability have so far been conducted exclusively with rodents in the laboratory setting. It is not known whether the same results will be observed in other taxa or in more natural foraging situations. Birds tend to be visual predators, and do not respond to changing prey abundance and densities in the same ways as mammals. Rather than preferentially choosing the most abundant food items, under certain situations birds may bias their prey choice towards the least abundant foods (Allen, 1988). Birds also may be constrained in their consumption habits to maintain a normal mass due to requirements for flight (Veasey, Metcalfe, \& Houston, 1998).

Here we expand on the experiments with rodents to include a species from another taxonomic group, a passerine bird, the European starling (Sturnus vulgaris). This bird is an introduced and ubiquitous species in North America, and displaces native birds from their nests as well as causing problems for humans. Tests were conducted using a known primary repellent, citronellyl acetate (Hile, 2004). In Experiment 1, we conducted tests in which we manipulated the number of bottles containing either plain water or repellent-treated water to determine whether we would obtain results with the birds that were similar to those found in rodents. In experiment 2 we used treated food rather than water.

\section{Methods}

\section{Subjects}

The subjects of these experiments were European starlings drawn from a colony of birds that had been trapped from the wild as adults of unknown age and uncertain gender. The birds were housed at the Monell Chemical Senses Center in group cages and maintained at $23{ }^{\circ} \mathrm{C}$ on a $14 \mathrm{~h}: 10 \mathrm{~h}$ light:dark cycle under broad-spectrum fluorescent lighting. Throughout both experiments, they had ad libitum access to commercial passerine food (Purina Small Bird Maintenance Diet) and fresh tap water (available from inverted glass bottles equipped with a trough at the base). Their meals were supplemented weekly with mealworms (Tenebrio larvae) and fresh apples. Starlings were weighed and examined weekly. Following weighing, any bill or nail overgrowth was trimmed, and birds were then allowed access to a bath. Subjects were housed singly in custom-built cages measuring $33 \times 33 \times 61 \mathrm{~cm}$. Individually-housed birds could see and hear other birds in the same room. For environmental enrichment, each cage contained hard plastic cat toys, which were changed weekly. The same birds were used in both experiments. Experiments were conducted with approval of the Institutional Animal Care and Use Committees at Monell (protocol ((1094) and at the National Wildlife Research Center (protocol (QA-1016).

\section{Experiment 1}

This experiment measured the effect on fluid intake and preference as a result of manipulating the number of bottles containing plain tap water (W) and repellent-treated water (R). Briefly, 3 of the treatments were 1,2, or 3 bottles out of 4 containing repellent (i.e., $1 \mathrm{~W}: 3 \mathrm{R}, 2 \mathrm{~W}: 2 \mathrm{R}$, and $3 \mathrm{~W}: 1 \mathrm{R})$. A fourth treatment was of 1 bottle each of plain and repellenttreated water $(1 \mathrm{~W}: 1 \mathrm{R})$.

During testing, the glass water bottles were replaced with $50 \mathrm{~mL}$ graduated and lidded glass bottles (BioServ, Frenchtown, NJ). These bottles were 9.5-cm high, 3.2-cm wide, and had a $4.5-\mathrm{cm}$ long extension from the base with a small opening $(2.5-\mathrm{cm}$ long $\times 1.5-\mathrm{cm}$ wide $)$ along the top of the extension from which birds could drink. Bottles were mounted along the front of each cage and were spaced $1.5 \mathrm{~cm}$ apart.

The repellent used here was the secondary plant compound, citronellyl acetate (CAS no. 150-84-5; Sigma Chemical Corp, St Louis MO) mixed at a $0.025 \%$ concentration by volume in tap water (its maximum solubility in water). Citronellyl acetate is an effective repellent to European starlings, and probably works via a primary mechanism (i.e., it is distasteful or an irritant; Hile, 2004). Each trial commenced at $1200 \mathrm{~h}$ and was $24 \mathrm{~h}$ in duration. There was a 1-or 2-day rest period between trials (during which, the birds had access to a single bottle of tap water). All birds $(n=24)$ were exposed to each of 4 treatments across 4 testing days: 4-bottle tests consisting of either 1, 2 or 3 bottles filled with tap water and the remainder filled with repellent-treated water $(1 \mathrm{~W}: 3 \mathrm{R}$, $2 \mathrm{~W}: 2 \mathrm{R}$ and $3 \mathrm{~W}: 1 \mathrm{R})$, or 1 bottle each of tap water and repellent-treated water $(1 \mathrm{~W}: 1 \mathrm{R})$. All 24 possible treatment orders across days were used. The position of repellenttreated and unadulterated water bottles within the array of bottles presented to each bird was randomized. Fluid levels were measured at the beginning of the trial and again after $24 \mathrm{~h}$. Intake was calculated to the nearest $1 \mathrm{~mL}$.

During the same period that tests were conducted, we placed containers of plain water and repellent-treated water in the bird room and recorded their change in volume over a 24-h period. This provided a measure of fluid evaporation.

\section{Experiment 2}

This experiment was similar to Experiment 1 except that bowls containing either the birds' normal food (F) or repellent-treated food $(\mathrm{R})$ were used, the number of subjects was 18, and 3 bowls were available. The repellent-treated food was prepared by mixing $40 \mathrm{~g}$ of citronellyl acetate ( $80 \%$ or more citronellyl acetate by weight) with $460 \mathrm{~g}$ of $95 \%$ ethanol. This mixture was poured over $1200 \mathrm{~g}$ of the birds' usual food, allowed to soak for $5 \mathrm{~min}$, drained, and then dried overnight in a hood. This method resulted in a concentration of $\sim 1 \%$ citronellyl acetate, which we had found to be repellent in an earlier, one-choice study, 
reducing consumption from a typical 4 or $5 \mathrm{~g}$ in $4 \mathrm{~h}$ trials to only $0.5 \mathrm{~g}$ (Hile, 2004).

On each experimental day, birds received one of 3 tests: (a) 2 bowls containing $50 \mathrm{~g}$ of plain food and 1 similarly filled with adulterated food (2F:1R), (b) 1 bowl of plain food and 2 bowls of adulterated food (2F:1R), or (c) 1 bowl of each (1F:1R). Bowls were equipped with partial lids and wired to the cage doors to prevent spillage. Bowls were $8.5 \mathrm{~cm}$ in diameter and $4.6 \mathrm{~cm}$ high, and the lids had a $3.2-\mathrm{cm}$ diameter hole in the top. The $50 \mathrm{~g}$ of food resulted in the bowls being roughly half-filled. Although previous work showed that these bowls reduce spillage to essentially nil, each bird's bedding was inspected following each trial for evidence of spilled food. Each starling received all 3 tests according to a balanced design. The position of bowls with respect to contents was randomized on each trial.

\section{Analysis}

Statistical analysis was performed using Statistica 6.1 (Statsoft, Tulsa, OK). Repeated measures ANOVAs were employed for both experiments for each solution or food type; Fisher's LSD tests were used in post-hoc analyses to determine where differences occurred among means. We also compared consumption of the alternatives to chance using 1-way t-tests. The comparisons against chance were based on the assumption that consumption should be equal among all available containers (for example, in the $3 \mathrm{~W}: 1 \mathrm{R}$ condition chance consumption of the repellent-treated water would be $25 \%$ ). All tests were 2-tailed and used a criterion for significance of $P<0.05$.

\section{Results}

\section{Experiment 1}

Repellent consumption varied significantly as a consequence of its relative availability $(F(2,44)=25.0$, $p<0.001$ ): Birds drank more repellent when 3 repellentcontaining bottles were available (1W:3R) than when 2 $(2 \mathrm{~W}: 2 \mathrm{R})$ or $1(3 \mathrm{~W}: 1 \mathrm{R})$ repellent-containing bottles were available. In a reciprocal relationship to repellent intake, water consumption varied as a consequence of the number of water bottles available $(F(2,44)=15.9, p<0.001)$. Birds drank less water when only 1 water bottle was available $(1 \mathrm{~W}: 3 \mathrm{R})$ than when $2(2 \mathrm{~W}: 2 \mathrm{R})$ or $3(3 \mathrm{~W}: 1 \mathrm{R})$ water bottles were available (Fig. 1). There was no significant difference between intake of water and repellent in the 2-bottle test (1W:1R).

Birds in our lab typically consume between 30 and $40 \mathrm{ml}$ of water in a $24 \mathrm{~h}$ period (Hile, unpubl. obs.), and they behaved similarly to this during the 2-bottle test, consuming $36.0 \pm 11.9 \mathrm{ml}$ of fluid overall. Birds drank significantly more total fluid $(46.1 \pm 2.2 \mathrm{ml})$ than this when 4 bottles were available $(t(23)=3.30 ; p<0.003)$.

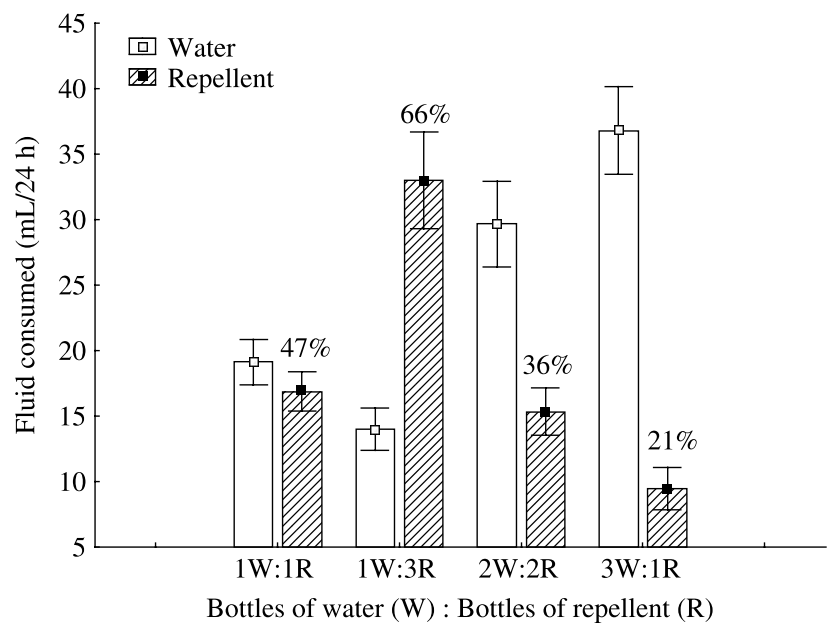

Fig. 1. Intake of water $(\mathrm{W})$ and $0.025 \%$ citronellyl acetate repellent $(\mathrm{R})$ by 24 starlings given various combinations of bottles of $\mathrm{W}$ and $\mathrm{R}$. Note: $1 \mathrm{~W}: 1 \mathrm{R}$ implies one bottle of water and 1 bottle of repellent, etc. Columns show the total intake from 1, 2, or 3 bottles. Values are means \pm SEMs. Percentages over each pair of bars are the preference ratios ( $\mathrm{R}$ intake/total intake $\times 100$ ).

Total fluid intake (i.e., the sum of all bottles available irrespective of content) was similar among the tests with 4 bottles, but lower in the test with only 2 bottles available $(F(1,23)=10.9, p=0.0031)$. Total fluid intake was $36 \pm$ $12 \mathrm{~mL}$ in the $1 \mathrm{~W}: 1 \mathrm{R}$ condition, and $47 \pm 19,45 \pm 18$, and $46 \pm 16 \mathrm{~mL}$ in the $1 \mathrm{~W}: 3 \mathrm{R}, 2 \mathrm{~W}: 2 \mathrm{R}$, and $3 \mathrm{~W}: 1 \mathrm{R}$ conditions, respectively.

During the $2 \mathrm{~W}: 2 \mathrm{R}$ test, only $36 \%$ of the birds' intake was repellent-treated water, which was less than the 50\% expected by chance $(t(23)=-3.18, p=0.0041)$. During the other 4-bottle tests, however, consumption did not vary significantly from chance $(67 \%$ under the $1 \mathrm{~W}: 3 \mathrm{R}$ and $21 \%$ under the $3 \mathrm{~W}: 1 \mathrm{R}$ condition). In the 2-bottle test, birds drank slightly less repellent-treated (47\%) than plain water, but this also did not deviate from chance (Fig. 1).

Loss of fluid due to evaporation was $<0.1 \mathrm{ml} / 24 \mathrm{~h}$ for water and $<0.1 \mathrm{ml} / 24 \mathrm{~h}$ for repellent. This was so small in relation to daily intakes that we did not adjust the data for this loss.

\section{Experiment 2}

The amount of treated food eaten differed according to the number of bowls of treated food available: $F(2,22)=8.1$, $p=0.0023$. Birds presented with 2 bowls of repellenttreated food $(1 \mathrm{~F}: 2 \mathrm{R})$ ate more of the treated food than they did during the other 2 tests (1F:1R and $2 \mathrm{~F}: 1 \mathrm{R})$. The amount of untreated food eaten also differed among tests: $F(2,22)=3.65, p=0.043$. Birds in the $2 \mathrm{~F}: 1 \mathrm{R}$ test ate more untreated food than they did in the 1F:2R test (Fig. 2).

Birds ate less repellent-treated food than expected by chance during both the $1 \mathrm{~F}: 1 \mathrm{R}(25 \% ; t(23)=3.20, p=0.008$; chance $=50 \%)$ and the $2 \mathrm{~F}: 1 \mathrm{R}(13 \% ; t(23)=5.19, p<0.001$; chance $=33 \%$ ) conditions, but did not stray significantly 


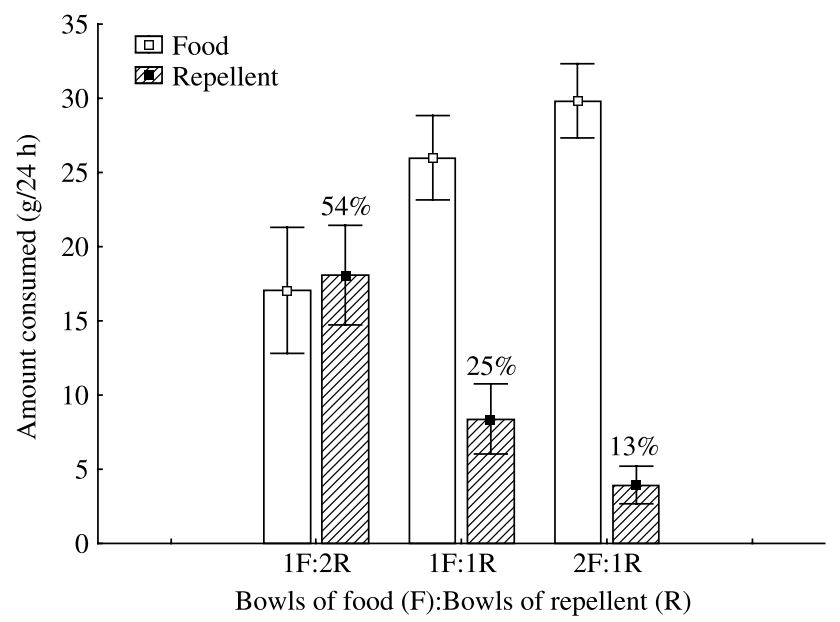

Fig. 2. Intake of untreated food (F) and $1 \%$ citronellyl acetate repellent $(\mathrm{R})$ by 18 starlings given various combinations of bottles of $F$ and $R$. Note: $1 F: 1 R$ implies one cup of untreated food and 1 cup of treated food, etc. Columns show the total intake from 1,2 , or 3 bottles. Values are means \pm SEMs. Percentages over each pair of bars are the preference ratios ( $R$ intake/total intake $\times 100$ ).

from chance when presented with the $1 \mathrm{~F}: 2 \mathrm{R}$ condition $(54 \%$; chance $=67 \%)$.

Total food intake (the sum of food and repellent-treated food from all available containers in a test) did not differ across tests $(F<1.0)$. Birds consumed $34 \pm 3 \mathrm{~g}$ of food during the $1 \mathrm{~F}: 1 \mathrm{R}$ condition, $34 \pm 7 \mathrm{~g}$ in the $2 \mathrm{~F}: 1 \mathrm{R}$ condition, and $35 \pm 6 \mathrm{~g}$ during the $1 \mathrm{~F}: 2 \mathrm{R}$ condition, which is similar to normal consumption for starlings in our lab. Finally, we found that spillage during Experiment 2 was negligible; we rarely observed any food on the bedding, and then only 1 or 2 crumbs.

\section{Discussion}

The results show that availability had a profound effect on the choice of fluids and foods consumed by European starlings. The amount of repellent consumed depended on the number of sources of repellent available as well as the number of sources of unadulterated water or food. If there were more sources of the repellent-treated than untreated item available, the birds appeared to be indifferent to the repellent.

Spillage is a significant concern when conducting experiments with multiple sources because this can compound to a significant amount of total intakes (Tordoff \& Bachmanov, 2003a, 2003b). In Experiment 1, fluid evaporation was minimal $(0.1 \mathrm{ml} /$ day $)$ and similar for the 2 types of fluid. However, since birds may have spilled more of the most abundant fluids, we were not able to rule out the differential effect of spillage. The higher total intake observed in the 4-bottle conditions versus 2-bottle condition may have been due to greater spillage, although, of course, it could also have been due to higher actual intakes, which has been observed before (Tordoff \& Bachmanov, 2003a). We cannot distinguish between these possibilities (see Tordoff \& Bachmanov, 2003a for discussion). However, spillage cannot explain the results of Experiment 2, involving solid foods, because spillage was easily quantified and essentially nonexistent. Therefore the present results cannot be accounted for by spillage.

Similarly, access to the alternative sources could not account for our results. In the tests with fluid, an excess of each alternative was available from adjacent inverted tubes, so access remained constant and equally easy. In the tests with food, we also allowed birds access to an overabundance of each type of food in easily accessible containers, and even the most preferred type was barely depleted during the 24-hour trial period.

To our knowledge, these are the first experiments to show this effect of abundance upon consumption in birds. Several avian species have been shown to choose the most abundant food regardless of nutritional value when prey densities are low ('apostatic' selection), but they bias their choice toward the least abundant option when densities are high ('antiapostatic' selection) (Allen \& Clark, 1968; Allen, 1988). This effect is thought to be characteristic of birds such as starlings, which are omnivorous but rely heavily on invertebrates, using visual cues to locate their prey. This bias is so strong in birds that visual cues generally supercede flavor cues in aversive learning paradigms (Wilcoxon, Dragoin, \& Kral, 1971), although there is some variation across species (Martin \& Lett, 1985). When visual differences among otherwise-similar alternative prey are subtle, however, the effect is not found (Weale, Whitwell, Raison, Raymond, \& Allen, 2000). Our paradigm represents a fairly high-density prey scenario (containers were immediately adjacent to one another), therefore it might be reasonable to expect the birds to choose the less common item, but in the absence of visual cues, they behaved more like herbivores.

There is some evidence that a similar phenomenon occurs with sheep (Parsons, Newman, Penning, Harvey, \& Orr, 1994). Sheep grazing from swards that were $20 \%$ clover and $80 \%$ grass ate a smaller proportion of their diet as clover than did those grazing from swards containing $50 / 50 \%$ or $80 / 20 \%$ clover:grass. The sheeps' food choice was not random and was not limited by shortages; there was sufficient clover in all 3 conditions so that the sheep could have consumed it exclusively if they had wanted to do so. The investigators considered and rejected several explanations for their finding, including 'partial preference', novelty, rarity, and 'sampling'.

Our results reinforce the obvious truth that preferences observed in the laboratory under a 2-bottle paradigm may have little bearing on preferences observed in real life. It is rare that an animal encounters only 2 food choices in the wild. There are ecological advantages to choosing food from several sources. Being familiar with many food sources may increase subsequent survival if a single food 
source becomes unavailable. Moreover, distributing intake over several sources, might thwart a predator lying in wait near a particular source. Finally, by consuming small amounts from several sources, the animal can reduce the chances of fatal poisoning because consumption of a poisonous source can be sufficiently low that little toxic exposure occurs before taste aversion conditioning produces avoidance.

In Experiment 1, the results of 3 of the 4 tests were consistent with the possibility that the birds could not detect the repellent in water. Their distribution of intakes did not differ from those expected if fluid was selected from each bottle by chance. However, this possibility is not supported by the results of the test with 2 bottles of water and 2 of repellent, in which the birds significantly avoided the repellent. We suspect that the concentration of citronellyl acetate used was not strongly repelling and that the $2 \mathrm{~W}: 2 \mathrm{R}$ test may have been the most sensitive test to assess this (see Tordoff \& Bachmanov, 2003a for discussion of test sensitivity). Alternatively, there is a possibility that the repellent is simply less salient in water than in food, as has been found in at least one other species (Gillette, Martin, \& Bellingham, 1980).

Our results have consequences for both the development and application of repellents. Efforts to develop new repellents have generally relied on either a 2-source or 1 -source ('no-choice') testing paradigm, with the consensus being that the 2 -source design is suited to detecting weak repellency, while a 1-source method is the gold standard for proving that a repellent is 'strong'. Our previous work with citronellyls using a traditional paradigm showed that citronellyl acetate is a strong repellent when used on food in a 1-source testing regimen (Hile, 2004), and here our results with food are consistent with those earlier findings. However, our results suggest that care must be taken in assuming that the results of such studies will be applicable to other situations.

The results of 1-or 2-source studies appear to be limited to the context in which they occur. Field application of repellents is a very different scenario than that encountered by caged animals in a 1-or 2-source testing apparatus. However, we do not yet know at what scale this phenomenon still holds. It is reasonable to expect that an intense and consistent within-field agricultural application of a repellent might prove to shift birds' choices toward the repellent. Whether a similar shift in choice might be seen on a landscape scale is impossible to predict.

The next step is to ask if our results apply at a larger scale. Specifically, are containers of food in a small cage surrogates for larger patches of land? How does the density of different resources affect choice behavior? Testing should be done varying the patch size of treated and untreated areas, and using different types of resources that are available in various densities, in order to answer this question.

\section{Acknowledgements}

The authors would like to thank Stanley Lewis for valuable input and technical assistance. A. A. Bachmanov, R. C. Beason, G. K. Beauchamp, and C. A. Forestell provided helpful input on the manuscript.

\section{References}

Allen, J. A. (1988). Frequency-dependent selection by predators. Philosophical Transactions of the Royal Society of London, 219, 485-503.

Gillette, K., Martin, G. M., \& Bellingham, W. P. (1980). Differential use of food and water cues in the formation of conditioned aversions by domestic chicks (Gallus gallus). Journal of Experimental Psychology: Animal Behavior Processes, 6, 99-111.

Hile, A. G. (2004). Avoidance of plant secondary compounds by European starlings: citronellyls. Crop Protection, 23, 973-978.

Martin, G. M., \& Lett, B. T. (1985). Formation of associations of colored and flavored food with induced sickness in five avian species. Behavioral and Neural Biology, 43, 223-237.

Parsons, A. J., Newman, J. A., Penning, P. D., Harvey, A., \& Orr, R. J. (1994). Diet preference of sheep: effects of recent diet, physiological state and species abundance. Journal of Animal Ecology, 63, 465-478.

Provenza, F. D., Villalba, J. J., Dziba, L. E., Atwood, S. B., \& Banner, R. E. (2003). Linking herbivore experience, varied diets, and plant biochemical diversity. Small Ruminant Research, 49, 257-274.

Tordoff, M. G. (2002). Obesity by choice: the powerful influence of nutrient availability of nutrient intake. American Journal of Physiology-Regulatory, Integrative and Comparative Physiology, 282, R1536-R1539.

Tordoff, M. G., \& Bachmanov, A. A. (2003a). Mouse taste preference tests: why only two bottles? Chemical Senses, 28, 315-324.

Tordoff, M. G., \& Bachmanov, A. A. (2003b). Influence of the number of alcohol and water bottles on murine alcohol intake. Alcoholism: Clinical and Experimental Research, 27, 600-606.

Veasey, J. S., Metcalfe, N. B., \& Houston, D. C. (1998). A reassessment of the effect of body mass upon flight speed and predation risk in birds. Animal Behaviour, 56, 883-889.

Wilcoxon, H. C., Dragoin, W. B., \& Kral, P. A. (1971). Illness-induced aversions in rat and quail: relative salience of visual and gustatory cues. Science, 171, 826-828.

Weale, M. E., Whitwell, D., Raison, H. E., Raymond, D. L., \& Allen, J. A. (2000). The influence of density on frequency-dependent food selection: a comparison of four experiments with wild birds. Oecologia, 124, 391-395. 